\title{
Paroxysmal itching in multiple sclerosis: a report of three cases
}

\author{
MITSUTOSHI YAMAMOTO, * SEISO YABUKI, $\dagger$ TOSHIYUKI HAYABARA, * \\ AND SABURO OTSUKI*
}

From the Department of Neuropsychiatry, Okayama University, Medical School, Okayama, Japan* and the Department of Neurology, Kochi Prefectural Central Hospital, Kochi, Japan†

SUMMARY Paroxysmal itching is described in three Japanese women with multiple sclerosis and previously reported cases are discussed. This paroxysmal symptom is rare, but may be the first and only symptom at the onset of multiple sclerosis.

Since Matthews ${ }^{1}$ first drew attention to tonic seizures as a paroxysmal symptom in multiple sclerosis (MS), various other kinds of paroxysmal events have been reported. ${ }^{2-7}$ These transient neurological symptoms are not uncommon during the course of MS, particularly in the early stage of the disease. ${ }^{2}$ They include paroxysmal dysarthria and ataxia, paraesthesiae and pain in the limbs, trigeminal neuralgia, and painful tonic seizure. Paroxysmal itching in MS is a rare symptom, first recognised by Osterman and Westerberg. ${ }^{5}$ Osterman ${ }^{8}$ later reported another two cases with paroxysmal itching in MS, while Yabuki and Hayabara ${ }^{7}$ reported one case in Japan. This case (3) is reviewed in the present report, together with a further two cases.

\section{Case reports}

Case 1 In January 1979, a Japanese woman aged 27 years was admitted to Okayama University Hospital with loss of vision on the left, and frequent attacks of itching affecting initially the lateral side of the right lower leg for two months. These were of sudden onset, lasted only a few minutes and ceased rapidly. The attacks occurred at least five times a day and were not relieved by scratching. Two weeks after the first attack, episodes of itching occurred on the lateral side of the left lower leg and continued for a week in this area. Thereafter, paroxysmal itching migrated to involve both knees, both hips and both lateral thighs. The itching was provoked in both legs whenever she had a hot bath.

Address for reprint requests: Dr Yamamoto, Department of Neuropsychiatry, Okayama University, Madical School, 2-5-1, Shikatacho, Okayama, Japan

Accepted 30 July 1980.
Continuous pain occurred on the medial side of both thighs. At that stage a physician and a dermatologist did not find signs of abnormality. In December 1978, she noted weakness of her left leg, and by January 1979 she also noted numbness of the left leg. Three days prior to admission she lost vision on the left and paroxysmal itching occurred in the $T 5,6$ segmental areas of her chest and back. Examination showed that physical abnormalities were confined to the nervous system. She was blind in the left eye. There were numbness, hyperalgesia, and hypaesthesia in both legs, and weakness of the right leg. The deep tendon reflexes were brisk, and both plantar responses were extensive. Lhermitte's sign was negative. Scratching scars were observed in her chest and left thigh (figure). Complete blood count, serological examination and other laboratory examinations were normal. Cerebrospinal fluid (CSF) was clear, with normal pressure, protein of $0.76 \mathrm{~g} / 1$ and five white blood cells per $1 \mu \mathrm{l}$ : CSF gamma globulin was $25 \cdot 3 \%$, CSF immunoglobulin-G was $0.068 \mathrm{~g} / 1$ (normal below $0.04 \mathrm{~g} / \mathrm{l}$ ). Treatment with prednisolone was begun. After two months, her vision was moderately improved, but paroxysmal itching still occurred every day and of ten at night. Carbamazepine $100 \mathrm{mg}$ a day was given and was increased to $700 \mathrm{mg}$ a day at which dose paroxysmal itching markedly decreased in frequency. Unfortunately, an allergic skin reaction developed which made a further treatment impossible. Paroxysmal itching recurred. Phenytoin and phenobarbitone also were given, but without effect and analgesics (aspirin and indomethacin) were also of no value. By August 1979, vision on the left side had completely recovered, but paroxysmal itching had increased in frequency and intensity. About that time, paroxysmal itching occurred in the medial side of both thighs together with continuous pain. In November 1979, vision on the left side was again moderately impaired. In February 1980, vision was normal, but about this time paroxysmal itching 


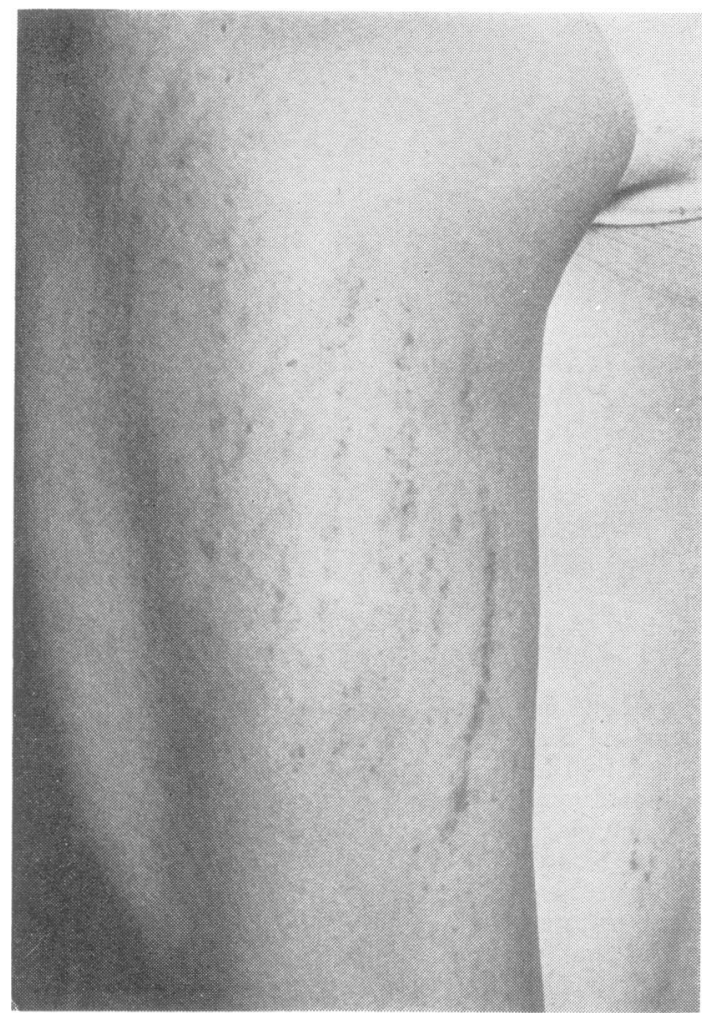

Figure Scratching scar in the lateral side of left thigh (Case 1).

recurred in the left parieto-temporal and became very intense. It lasted for 19 days, and on the day when paroxysmal itching ceased, a left hemiplegia occurred, and superficial sensation on the right side was lost below the C3 segment. After five days, a total quadriplegia with sensory loss below the $\mathrm{C} 3$ segment developed and respiration was laboured. By May 1980, she had recovered moderately from the quadriplegia and sensory disturbances, but paroxysmal itching recurred and was provoked by touch in the C3 dermatome.

Case 2 In May 1979, a Japanese woman aged 54 years was admitted to Kochi Prefectural Central Hospital for difficulty in walking. One month prior to admission she had had a fever for a week, followed by numbness, slight muscle weakness in both hands and vertigo when walking. Muscle weakness in both legs progressed, so that she could not stand up. Three days later, numbness in the fingers of both hands extended to involve both forearms. On admission to hospital, she could not walk and had paraesthesia in her chest. Muscle weakness was noted in both hands, and superficial sensory disturbance was present below $\mathrm{T} 2$ segment on the right and T4 on the left. Deep tendon reflexes were brisk. Babinski signs and ankle clonus were present bilaterally. Lhermitte's sign was present. There were no cerebellar signs. Blood count revealed white blood cells 6400 per $1 \mu$ l with slight eosinophilia (8\%). Serological examination revealed a high value of immunoglobulin-E, $2200 \mu$ per $\mathrm{ml}$ (normal below $500 \mu$ per $\mathrm{ml}$ ). Her past history revealed bronchial asthma. CSF was normal. On June 8, at the moment of changing her position in bed, paroxysmal itching first occurred at the back of neck, on the back and on both arms, lasted about 10 to 20 seconds, then disappeared. About that time, her neurological disturbances improved. Paroxysmal itching occurred in both shoulders and both arms (and occasionally in the upper back), sometimes unilateral, sometimes bilateral. The attacks lasted for about 20 seconds and always occurred at the start of movement. Hyperventilation did not provoke paroxysmal itching. She was given carbamazepine $300 \mathrm{mg}$ a day. Paroxysmal itching did not recur thereafter. After three weeks administration, carbamazepine was stopped and paroxysmal itching recurred. Carbamazepine was begun again. In December 1979, it was stopped, and thereafter paroxysmal itching did not recur.

Case 3 In September 1976, a Japanese woman aged 37 was admitted to Kochi Prefectural Hospital for sensory disturbance. In the evening, 36 days prior to admission the patient felt a smarting pain in her lower leg when she stood up. The pain lasted about 10 seconds, but did not impair her ability to walk. For the next four days paroxysmal dysaesthesia below her left knee occurred several times a day. Thereafter, her left shoulder felt heavy on awaking, and a smarting pain also occurred throughout her arm, lasting about 10 to 20 seconds. On examination initially vertical nystagmus was noted and no other abnormality was found. After her first visit to hospital, paroxysmal itching began to occur in the face, and she became unstable when walking. On admission, physical abnormalities were confined to the nervous system. Vertical nystagmus on left lateral gaze was present. This was bilateral intention tremor, and the finger-nose test was very clumsily performed, especially on the left She could not walk because of severe truncal ataxia. The jaw and deep tendon reflexes were bilaterally hyperactive and the right plantar response was extensive. Left C3 segmental hypaesthesia and paraesthesia were present and there was hypaesthia and paraesthesia of the left arm, left trunk and left leg. Deep sensation was moderately diminished in both legs. Lhermitte's sign was negative. Scratching scars were present on her face. Complete blood count was normal, as was examination of the CSF. Paroxysmal itching occurred for about 10 days, but then trigeminal neuralgia developed, which was effectively treated by carbamazepine. In November 1976, when she overbreathed during EEG recording, a tonic seizure affecting the right arm and leg occurred, so phenytoin was added to carbamazepine. Subsequently her neurological 
symptoms improved except the vertical nystagmus, intention tremor and extensor plantar responses, and paroxysmal itching did not recur.

\section{Discussion}

Itching may occasionally be an important symptom of systemic disease, ${ }^{910}$ such as allergy, drug reaction, and intestinal and tissue parasites, but is a rare symptom in neurological diseases. Itching may occur in the pre-eruptive phase of herpes zoster, and may be an occasional feature of tabes dorsalis. ${ }^{11}$ In the three Japanese women described here with MS, laboratory and physical examinations showed that there were no systemic diseases, allergy, drug reaction, or emotional stress relating to their itching.

The common features of our three patients were as follows: (1) The attacks occurred and ended abruptly in all cases, (2) their duration ranged from several seconds to several minutes, (3) their frequency was five to six times a day and sometimes more, (4) the attacks often occurred during sleep, awaking the patient, (5) the distribution of the attacks involved the face, trunk and extremities: They were often symmetrical and segmental, (6) superficial sensory disturbances were present in the areas affected in all patients, (7) the attacks were sometimes provoked at the start of movement, (8) continuous pain changed to paroxysmal itching in one patient, and paroxysmal itching changed to trigeminal neuralgia in another, (9) carbamazepine was effective in two patients, (10) paroxysmal itching appeared as the first and only symptom at the onset of MS and a predictive symptom of exacerbation of MS in one patient.

These features are similar to those of other types of paroxysmal symptoms in MS. The duration of paroxysmal attacks such as tonic seizures and sensory seizures varies from a few seconds to several minutes. ${ }^{256}$ The duration of paroxysmal itching varied from several seconds to several minutes in our cases although the majority lasted less than a minute. Tonic seizures and painful tonic seizures were recognised to be closely correlated with Lhermitte's sign, ${ }^{312}$ and Osterman $^{8}$ also suggested a correlation between paroxysmal itching and Lhermitte's sign, which is an indication of pathological processes affecting the posterior column of the cervical cord. ${ }^{13} 14$ Whether there is a correlation between the occurrence of paroxysmal symptoms and other neurological symptoms is in dispute. Osterman ${ }^{8}$ reported that neurological examination between bouts revealed only minor abnormalities, but Yabuki et $a^{15}$ reported that tonic seizures tended to occur during exacerbations of MS. However, Osterman and Westerberg ${ }^{12}$ also reported that examination during the period of tonic seizures did not reveal any abnormality in two of five cases. Shibasaki and Kuroiwa ${ }^{3}$ reported that painful tonic seizures occurred in parallel with or in close proximity to clinical exacerbation of spinal cord lesions. In our cases, paroxysmal itching occurred as the first symptom at the onset of MS, and a predictive symptom just before exacerbation in one patient. It also occurred during the recovery course of MS (two patients) and prior to exacerbation (two patients).

Though the similarities of the various paroxysmal symptoms in MS suggest similar pathogenic mechanisms, there are various theories as to their causes. ${ }^{245}$ Osterman and Westerberg ${ }^{5}$ proposed that paroxysmal attacks in MS were caused by transversely spreading ephaptic activation of axons within a partially demyelinated lesion. Matthews, ${ }^{6}$ and Yabuki and Hayabara $^{7}$ also considered this idea compatible with the observation that many paroxysmal attacks in MS seem to be precipitated by sensory stimuli or movement. Paroxysmal itching was always provoked by having a hot bath in one of our patients, and the aggravation of symptoms of MS by raising body temperature has long been recognised. ${ }^{16}$ In this patient (case 1) paroxysmal itching tended to occur at night, when her body temperature rose 0.5 to $1.0^{\circ} \mathrm{C}$ compared with day time. Heat itself also produces itching, ${ }^{10}$ but itching in this patient was not due to a generalised skin reaction to a hot bath because the itching skin areas were localised. Paroxysmal itching also was provoked at the start of movement in two patients.

It is generally agreed that stimuli provoking itching give rise to impulses carried principally by unmyelinated, slow conducting fibres of the C groups to a central neuronal pool in the spinal cord via the posterior roots of the spinal nerves, and that pain fibres carry the sensation of itching in the sensory spinal nerve to the spinothalamic tract and thence to the thalamus. ${ }^{1718}$ Some observers have suggested that itching is a subthreshold pain sensation. ${ }^{11} \mathrm{C}$ unit activity was recorded with microelectrodes from intact sensory fascicles in the human peroneal nerve by Torebjörk, ${ }^{19}$ who found that the sensations produced by stimuli inducing intense afferent $\mathrm{C}$ unit activity were reported as "burning or delayed pain", whereas stimuli eliciting low frequency activity often were reported as "itch". 
Osterman ${ }^{8}$ reported that one patient experienced both paroxysmal pain and paroxysmal itching within the same skin area. In our cases, one patient experienced both paroxysmal itching and continuous pain within the same skin areas, another patient experienced both paroxysmal itching and trigeminal neuralgia within the same area of her face. Clinically, these findings suggested that sensations of itching and pain were closely related.

\section{References}

1 Matthews WB. Tonic seizures in disseminated sclerosis. Brain 1958; 81:193-206.

2 McAlpine D. Symptoms and signs. In: McAlpine D, Lumsden CE, Acheson ED, eds. Multiple sclerosis. A reappraisal. Second edition. Edinburgh: Churchill Livingstone, 1972: 132.

3 Shibasaki H, Kuroiwa Y. Painful tonic seizures in multiple sclerosis. Arch Neurol 1974; 30:4751.

4 Miley CE, Forster FM. Paroxysmal signs and symptoms in multiple sclerosis. Neurology (Minneap) 1974; 24:458-61.

5 Osterman PO, Westerberg CE. Paroxysmal attacks in multiple sclerosis. Brain 1975; 98: 189-202.

6 Matthews WB. Paroxysmal symptoms in multiple sclerosis. J Neurol Neurosurg Psychiatry 1975; 38:617-23.

7 Yabuki S, Hayabara T. Paroxysmal dysesthesia in multiple sclerosis. Folia Psychiatr Neurol Jpn 1979; 33:97-104.

8 Osterman PO. Paroxysmal itching in multiple sclerosis. Br J Dermatol 1976; 95:555-8.

9 Fitzpatrick TB, Johnson DP. Fundamentals of dermatologic diagnosis. In: Fitzpatrick TB, Arndt $\mathrm{KA}$, Clark WH et al, eds. Dermatology in general medicine. New York: McGraw-Hill, 1971: 10.
10 Herndon JH Jr. Pruritus. In: Dermis DJ, Dofson RL, McGuire J, eds. Clinical dermatology, vol 4. New York: Harper \& Row, 1977: Unit 29-2.

11 Cairns RJ. The skin and the nervous system. In: Rook A, Wilkinson DS, Ebling FJG, eds. Textbook of dermatology. Second edition. Oxford: Blackwell, 1972: 1971.

12 Kuroiwa Y, Araki S. Lhermitte's sign and reflex tonic spasm in demyelinating disease with special reference to their localising value. Kyushu J Med Sci 1963; 14:29-38.

13 Lhermitte J, Bollak J, Nicolas M. Les douleurs à type de décharge électrique consécutives à la flexion céphalique dans la sclérose en plaques: Un cas de forme sensitive de la sclerose multiple. Rev Neurol 1924; 31:56-62.

14 Alajournine TH, Thurel R, Papaioanou C. La douleur à type de decharge électrique, provoquée par la flexion de la tête et parcourtrant le corps de haut en bas. Rev Neurol 1949; 81:89-97.

15 Yabuki S, Hayabara $\mathrm{T}$, Ikeda $\mathrm{H}$ et al. Clinical observation of the tonic seizure in multiple sclerosis. Seishin Shinkeigaku Zasshi (in Japanese) 1974; 76:207-20.

16 McAlpine D. Some aspects of the natural history (continued). In: McAlpine D, Lumsden CE, Acheson ED, eds. Multiple sclerosis. A reappraisal second edition. Edinburgh: Churchill Livingstone, 1972: 99.

17 Sweet WH. Pain. In: Field J, Maoun HW, Hall VE, eds. Handbook of Physiology: Section I, Neurophysiology. Washington: American Physiological Society, 1959; vol 1, 459.

18 Lotincz AL. Neurophysiologic reactions of the skin: Pathophysiology of pruritus. In: Fitzpatrick TB, Arndt KA Clark WH et al, eds. Dermatology in general medicine. New York: McGraw-Hill, 1971: 212.

19 Torebjörk HE. Afferent C responding to mechanical, thermal chemical stimuli in human non-glabrous skin. Acta Physiol Scand 1974; 92:374-90. 